\title{
Predictive Model for Likelihood of Survival of Sickle-Cell Anaemia (SCA) among Peadiatric Patients using Fuzzy Logic
}

\author{
Adebayo Peter Idowu ${ }^{1}$, Theophilus Adesola Aladekomo ${ }^{2}$, Kehinde Oladipo Williams ${ }^{3}$ and Jeremiah \\ Ademola Balogun ${ }^{3}$ \\ ${ }^{1}$ Department of Computer Science \& Engineering, Obafemi Awolowo University, Ile-Ife, Nigeria, \\ ${ }^{2}$ Department of Peadiatric and Child Health, Obafemi Awolowo University, Ile-Ife, Nigeria, \\ ${ }^{3}$ Department of Physical and Computer Sciences, College of Natural and Applied Sciences, McPherson \\ University Ajebo, Ogun State, Nigeria. \\ paidowu1@gmail.com; aladekomotheo@yahoo.com; kehindewilliams@yahoo.com; \\ jeremiahbalogun@gmail.com
}

\begin{abstract}
A fuzzy logic-based system has been applied to a number of cases in medicine especially in the area of the development of diagnostic systems and has been discovered to produce accurate results. In this paper, a fuzzy logic-based system is presented which is used to simulate a prediction model for determining the likelihood of Sickle Cell Anemia (SCA) in individuals given a 3-tuple record containing the level of fetal haemoglobin, genotype and the degree of Anemia.

Knowledge was elicited from an expert at Federal Medical Centre, Owo, Ondo State, Nigeria and was used in developing the rule-base and simulated the prediction model using the MATLAB software. The results of the fuzzification and defuzzification of variables, inference engine definition and model testing was also presented and showed that the fuzzy logic based model will be very useful in the prediction of the likelihood of Sickle Cell Anemia (SCA) among Nigerian patients.
\end{abstract}

Keywords: fuzzy logic, prediction model, sickle-cell disease, likelihood

\section{Introduction}

According to Obeagu et al (2014) sickle cell disease (SCD) is a hereditary blood disorder which can be easily identified as an abnormal, sickle-shaped form of the red blood cells. A complication called sickling arises due to the cells' flexibility caused by the sickle shape and reduces the lifespan of an average male and female to 42 and 48 years respectively. If this sickling condition is well-managed, there are cases where such a person may live up to 8 decades. The disease is also discovered to be very rampant among tropical and sub-tropical sub-Saharan regions where there used to be malaria (Wellems et al, 2003). SCA may lead to various acute and chronic complications, several of which have a high mortality rate (Malowany et al, 2012). People with sickle cell disease may also develop anemia including some jaundice and body pains.

Three quarters of sickle-cell cases occur in Africa. A recent WHO report estimated that around $2 \%$ of newborns in Nigeria were affected by sickle cell anaemia, giving a total of 150,000 affected children born every year in Nigeria alone. The carrier frequency ranges between $10 \%$ and $40 \%$ across equatorial Africa, decreasing to $12 \%$ on the North-African coast and $<1 \%$ in South Africa (Obeagu et al, 2014). Sickle Cell is a major cause of morbidity and mortality in Africa where there is no readily effective treatment (Omoti, 2005).Patients with sickle cell disease have varying amounts of 
Kehinde Oladipo Williams, Theophilus Adesola Aladekomo and Adebayo Peter Idowu; Prediction Model for Likelihood of Survival of Sickle-Cell Anaemia (SCA) among Peadiatric Patients using Fuzzy Logic, Transactions on Networks and Communications, Volume 3 No 1, Feb (2015); pp: 31-44

abnormal haemoglobin called the sickle cell in their erythrocytes. Sickle cell anaemia is due to the substitution of adenine with thymine in the glutamic DNA codon, which results in turn, in substitution of valine for glutamic acid in position of beta globin chain (Pauling et al., 1949).

The disease amounts for over $60 \%$ of the world's major haemoglobinopathies with an estimated 2-3 million Nigerians affected by the $\mathrm{S}$ gene (Olatunji, 2002).The extent of the problems of sickle cell disease in Nigeria cannot therefore be overemphasized because of the $S$ gene said to be between 25-30\%. The majority of patients born to rural dwellers do not usually survive childhood (Ukpong, 1992).

Fuzzy logic is a means of providing a path for the diagnosis and decision making process due to its ability to deal with uncertainties (fuzziness) and ambiguity which may exist in the knowledge and information relating to a domain of study. Today, medical practitioners have identified possible and promising areas for implementing fuzzy logic systems for medical diagnosis Mishra et al, 2014). The idea of Fuzzy logic was presented by Lofti A Zadehn in 1965 based on the fuzzy set theory. Fuzzy logic systems are implemented by the manipulation of membership functions which simulate variables by the inference engine (rule-base).

Membership functions (MF) are curves that defines how each point in the input and output space is mapped to a membership value (or degree of membership) between 0 and 1.This implies that for every label of each variable; a membership function will be used to define the level of membership of the value entered with respect to the degree of membership to the label. Unlike, classical set; a fuzzy logic may be defined as follows:

If $X$ is a universe of discourse and its elements are denoted by $X$, then a fuzzy set $A$ in $X$ is defined as a set of ordered pair:

$$
A=\left\{x, \mu_{A}(x) \mid x \in X\right\}
$$

$\mu_{A}(x)$ is called a membership function (or MF) of $\mathrm{x}$ in A. The membership function maps each element of $X$ to a membership function value between 0 and 1 . For the purpose of this study, the following must be noted:

- The set A is any input (sickle-cell factors) or output (sickle-cell likelihood) variable considered for this study;

- The set $X$ is the set of values for which a variable is valid, for example a set $A=\operatorname{degree}$ of Anemia will be valid for value $x=0$ for No and $x=1$ for Yes. Hence for the set $A$, the set $X$ is the set containing $\{0,1\}$; and

- $\mu_{A}(x)$ is the map of the membership function that will be used to plot the degree of membership.

Furthermore, there is no widely acceptable and readily available cure for patients with sickle cell anaemia at present. Curable methods such as gene therapy and bone marrow transplantation, which may be associated with several complications, are not readily available in developing nations (Omoti, 2005). This disease is a serious threat to human life and it is believed that such tragedy can be reduced by early diagnosis of its existence, hence this study.

This paper is aimed at developing a fuzzy logic based system that predicts the likelihood of sickle cell disease in an individual by requesting for a 3-tuple record consisting of the Level of fetal haemoglobin, Genotype and the degree of Anemia. The study is limited to knowledge elicited from 
a physician located in western Nigeria based on experience gathered in the diagnosis of the likelihood of sickle cell disease in patients in western Nigeria.

\section{Related Works}

Goyal, D. (2006) worked on the development of a disease diagnostic system using LabVIEW. The work was based on the use of fuzzy logic to diagnose the various kinds of anemia using the concept of fuzzy logic in the LabVIEW platform. The proposed system made use of 12 input variables which all had their respective labels: haemoglobin units, hematocrit units HMCT), mean corpuscular volume (MCV), mean corpuscular hemoglobin concentration (MCHC), reticulocyte count (RCC), while blood cells (WBC), platelets (PLT), total Iron Binding Capacity (TIBC), serum Iron (SEI), Nucleated red cells (NRC), hyper segmented white cells (HSWC) and ringed sideroblast in bone marrow (RSBM). The system was simulated on the LABVIEW platform and a fuzzy logic system containing 12 input variables was used to predict 18 different types of anemia. After series of test, the system was discovered to produce excellent results in the diagnoses of cases collected from the laboratory.

Sayyahi (2008) worked on an application of fuzzy cased based reasoning for poison classification. The system was developed with the aim of recognizing, controlling and treating a limited poison case. The system developed for the classification of poison involved the combination of fuzzy logic and case-based reasoning - the case based reasoning system was developed which incorporated the use of fuzzy logic. The variables used as inputs were symptoms categorized as: general, psychological, cardiovascular, respiratory and gastrointestinal. The system was discovered to identify the different types of poison for which information was provided by the physician although, its results are still subject to the physician's decision to accept or reject (if he feels otherwise).

Aramideh et al (2014) worked on the application of fuzzy logic for the development of an expert system to diagnose anemia. The fuzzy model was developed using 5 input variables namely: tachycardia, irritability, memory weakness, nose bleeding and chronic fatigue. The fuzzy system also has 3 different outputs which identify 3 different types of anemia namely: iron deficiency, folic acid deficiency and sickle-cell. The inference engine of the fuzzy model contained 42 rules which were modeled using the 5 input and 3 output variables. The authors also suggest that additional symptoms of anemia could help produce a more effective model.

Mishra et al (2014) developed a fuzzy logic model using the Mamdani model for the effective diagnosis of sickle-cell disease. The model developed used rules that were generated based on support sets from patients who belong to three classes: patients with primary SCD, secondary SCA and without SCD. The diagnostic system used three input variables namely: symptom score expressed as a percentage of severity of symptoms, haemoglobin A and haemoglobin S. The results showed that the fuzzy model improves results compared to other existing models. It was also discovered to be capable, efficient and cost effective in diagnosing SCD.

\section{Materials and Methods}

\subsection{Research design}

In this paper, a fuzzy logic-based prediction model is proposed with the aim of predicting the likelihood of sickle-cell disease in individuals. In order to achieve this, the research design presented in Figure 1 was used. The study started with the identification of the problem of predicting sickle cell likelihood given a number of symptoms/factors considered as input variables ( 3 in all). A review of related literature was performed to identify understand sickle cell diseases and its symptoms in addition to related works done in the past. Following this, knowledge was elicited from an expert 
Kehinde Oladipo Williams, Theophilus Adesola Aladekomo and Adebayo Peter Idowu; Prediction Model for Likelihood of Survival of Sickle-Cell Anaemia (SCA) among Peadiatric Patients using Fuzzy Logic, Transactions on Networks and Communications, Volume 3 No 1, Feb (2015); pp: 31-44

(medical practitioner) located at the Federal Medical Centre, Owo, Ondo State in understanding and verifying the information concerning sickle cell symptoms.

The elicited knowledge was used to build the inference engine of the proposed system - this is part of the model formulation technique which also includes the fuzzification of the input and output variables. the model formulation is made complete by the identification of the aggregation method chosen for the inference engine alongside the defuzzification method required for producing the output variable which is the likelihood of sickle-cell disease (No and Yes)

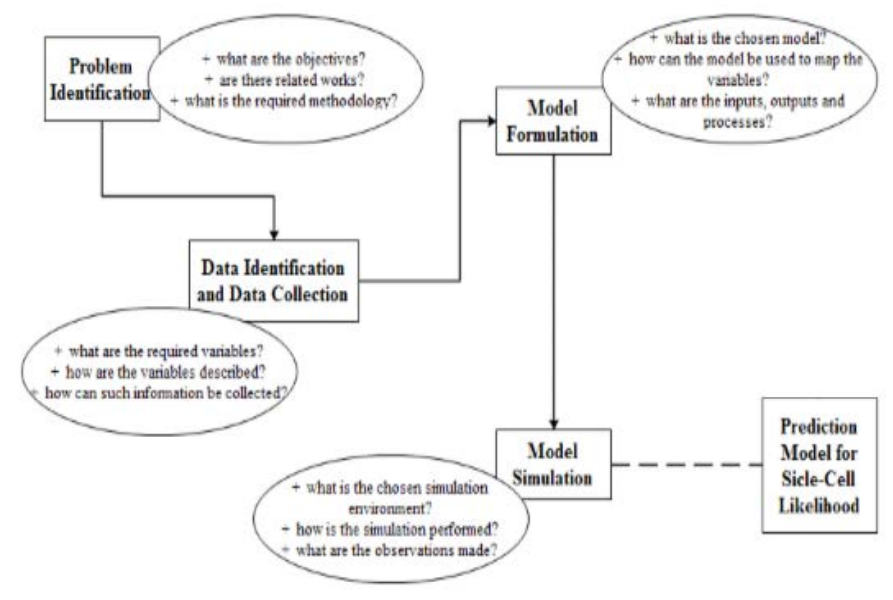

Figure 1: Research design for the study

\subsection{Data identification and collection}

A number of symptoms/factors are known to be connected to sickle cell disease, among all these factors only 3 were identified as being the most important and relevant symptoms: the level of fetal haemoglobin, genotype and the degree of anemia. This information was collected via structured interview with the medical practitioner who identified the factors and emphasized 3 main factors which are most easily used in identifying the likelihood of sickle cell disease based on his experience in medical practice. The fetal haemoglobin is defined as either: less than $2 \%$, between $2 \%$ and $5 \%$, and greater than 5\%; the genotype was classified as either SS, S* and SA while the degree of anemia is classified as either less than $15 \%$ and greater than or equal to $15 \%$.

In addition to the identification of the data variables, an understanding of the pattern of distribution was important in identifying the best membership function that could be used in plotting the labels of each variables. The number of rules required by the fuzzy logic inference system was calculated by multiplying the labels of each variable with each other; therefore we have $3 * 3 * 2=18$ different rules. This information was necessary in the development of the fuzzy logic inference system.

\subsection{Fuzzy logic model formulation}

Fuzzy logic systems have the ability to decide and control a system using the knowledge of an expert. Fuzzy logic systems are mostly profitable in systems with sophisticated environments where a clear and obvious model of the system is not achievable.

In order to develop the fuzzy logic system required for the prediction of the likelihood of sickle-cell disease, a number of activities are needed to be accomplished. The Fuzzy Logic System available in the Fuzzy Logic Toolbox of the MATLAB R2012a software has three parts (see Figure 2): 
- A set of Inputs represented by their respective membership functions;

- An Inference Engine which contains the IF-THEN rules (domain knowledge); and

- An Output represented by its membership functions.

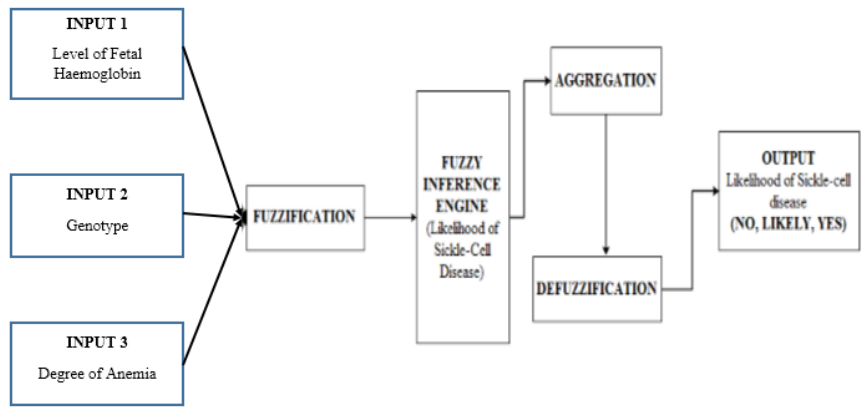

Figure 2: Schematic diagram of the proposed model

The membership functions will be used to map the values of each input and output variables into a $[0,1]$ interval with the use of triangular and trapezoidal membership functions (where appropriate); this process is referred to as a Fuzzification process. After Fuzzification; the fuzzified inputs must be mapped to the fuzzified output via the use of operators (AND, OR and NOT) to develop IF-THEN rules that describe the relationship between every input (sickle-cell likelihood factors) and output (likelihood of the disease) variable. The different rules are used to generate different results which are then aggregated to just one fuzzified output. This fuzzified output will then be defuzzified using the centroid method which selects the centre of the polygon to determine the label of the output variable as Yes, Likely or No.

The most prominent reasons that justify the use of fuzzy logic systems today are (Aramideh et al, 2014):

a) The sophistication of the natural world which leads to an approximate description or a fuzzy system for modeling; and

b) The necessity of providing a pattern to formulate mankind knowledge and applying it to actual systems.

The process of development of the fuzzy inference system needed for the prediction of sickle-cell disease may summarized as follows:

i. Fuzzification of inputs and outputs;

ii. Construction of the inference engine;

iii. Rule aggregation; and

iv. Defuzzification of output variables.

\subsection{Defining membership functions}

Before the process of Fuzzification, it is very important to properly describe the crisp values that was used in mapping the values of the membership function which was be needed by the fuzzy logic system. For the discrete variables with nominal values or Boolean (yes/no) - the values: $0,1,2 \ldots \ldots$ $\mathrm{n}-1$ was assigned to each value for $\mathrm{n}$ labels; this is the case for Genotype as $\mathrm{SS}=0, \mathrm{SE}=1$ and $\mathrm{S}^{*}=2$. For the continuous variables which are measured; a value of the percentage expressed as a proportion of 1 was used, i.e. $10 \%$ and $56 \%$ read as 0.10 and 0.56 respectively into the appropriate membership 
Kehinde Oladipo Williams, Theophilus Adesola Aladekomo and Adebayo Peter Idowu; Prediction Model for Likelihood of Survival of Sickle-Cell Anaemia (SCA) among Peadiatric Patients using Fuzzy Logic, Transactions on Networks and Communications, Volume 3 No 1, Feb (2015); pp: 31-44

functions. Table 1 gives a description for the values of the labels to be used for each variable along with their respective membership functions.

Table 1: Description of the labels for each variables

\begin{tabular}{|c|c|c|c|c|c|c|}
\hline № & Variables & \multicolumn{4}{|c|}{ Membership function mapping (label = value) } & \multirow{2}{*}{$\begin{array}{c}\begin{array}{l}\text { Membership } \\
\text { function }\end{array} \\
\text { Trapmf }\end{array}$} \\
\hline 1 & $\begin{array}{l}\text { Level of Fetal } \\
\text { Haemoglobin }\end{array}$ & $\begin{array}{c}<=2 \% \\
\text { becomes } \\
<=0.02 \\
\Rightarrow x_{1} \leq 0.02\end{array}$ & $\begin{array}{r}2 \% \\
\quad 2 \\
0.02 \\
\Rightarrow \quad 0.0\end{array}$ & $\begin{array}{l}=5 \% \\
5 \\
=0.05 \\
\leq 0.05\end{array}$ & $\begin{array}{c}>5 \% \\
\text { becomes } \\
>0.05 \\
\Rightarrow x_{1}>0.05\end{array}$ & \\
\hline 2 & Type of Genotype & $\begin{array}{c}\mathrm{SS} \\
\Rightarrow x_{2}=0\end{array}$ & & & $\begin{array}{c}\mathrm{S}^{*}=2 \\
\Rightarrow x_{2}=2\end{array}$ & Trimf \\
\hline 3 & Degree of Anemia & \multicolumn{2}{|c|}{$\begin{array}{c}<15 \% \text { becomes }<0.15 \\
\Rightarrow x_{3}<0.15\end{array}$} & \multicolumn{2}{|c|}{$\begin{array}{c}>=15 \% \text { becomes }>=0.15 \\
\Rightarrow x_{3} \geq 0.15\end{array}$} & Trapmf \\
\hline 4 & Likelihood of SCD & \multicolumn{2}{|c|}{$\begin{array}{c}\text { No } \\
\Rightarrow y=0\end{array}$} & \multicolumn{2}{|c|}{$\begin{aligned} & \text { Yes } \\
\Rightarrow & y=1\end{aligned}$} & Trimf \\
\hline
\end{tabular}

\subsection{Fuzzification of the variables}

For the purpose of this study, the triangular and trapezoidal membership functions were used to map the degree of membership of the labels of each variable used both input and output variable. Following is a description of each variable and the type of membership function used for the labels alongside the ordered pair that was used in mapping the degree of membership for each variable's label.

a. Level of Fetal Haemoglobin, x1 (Figure 3)

- $x_{1} \leq 0.02 \quad-\quad \operatorname{trapmf}[x 1 ;-0.36,-0.004,0.016,0.02]$

$$
\begin{aligned}
& \operatorname{trapmf}[\mathrm{x} 1 ;-0.36,-0.004,0.016,0.02] \\
& =\left\{\begin{array}{cc}
\frac{x 1+0.36}{0.356}, & -0.36 \leq x 1 \leq-0.004 \\
1, & -0.004 \leq x 1 \leq 0.016 \\
\frac{0.02-x 1}{0.004}, & 0.016 \leq x 1 \leq 0.02 \\
0, & 0.02 \leq x 1
\end{array}\right\}
\end{aligned}
$$

- $0.02<x_{1} \leq 0.05 \quad-\quad \operatorname{trapmf}[x 1 ; 0.0186,0.0202,0.0376,0.0476]$

trapmf[x1; 0.0186, 0.0202, 0.0376, 0.0476]

$$
=\left\{\begin{array}{cc}
\frac{x 1-0.0186}{0.0016}, & x 1 \leq 0.0186 \\
1, & 0.0186 \leq x 1 \leq 0.0202 \\
\frac{0.0476-x 1}{0.01}, & 0.0202 \leq x 1 \leq 0.0376 \\
0, & 0.0476 \leq x 1
\end{array}\right\}
$$

- $\quad x_{1}>0.05$

$\operatorname{trapmf}[x 1 ; 0.05,0.062,1.142,1.462]$ 
trapmf $[\mathrm{x} 1 ; 0.05,0.062,1.142,1.462]$

$$
=\left\{\begin{array}{cc}
\frac{x 1-0.05}{0.012}, & x 1 \leq 0.05 \\
1, & 0.05 \leq x 1 \leq 0.062 \\
\frac{1.462-x 1}{0.32}, & 1.142 \leq x 1 \leq 1.462 \\
0, & 1.462 \leq x 1
\end{array}\right\}
$$

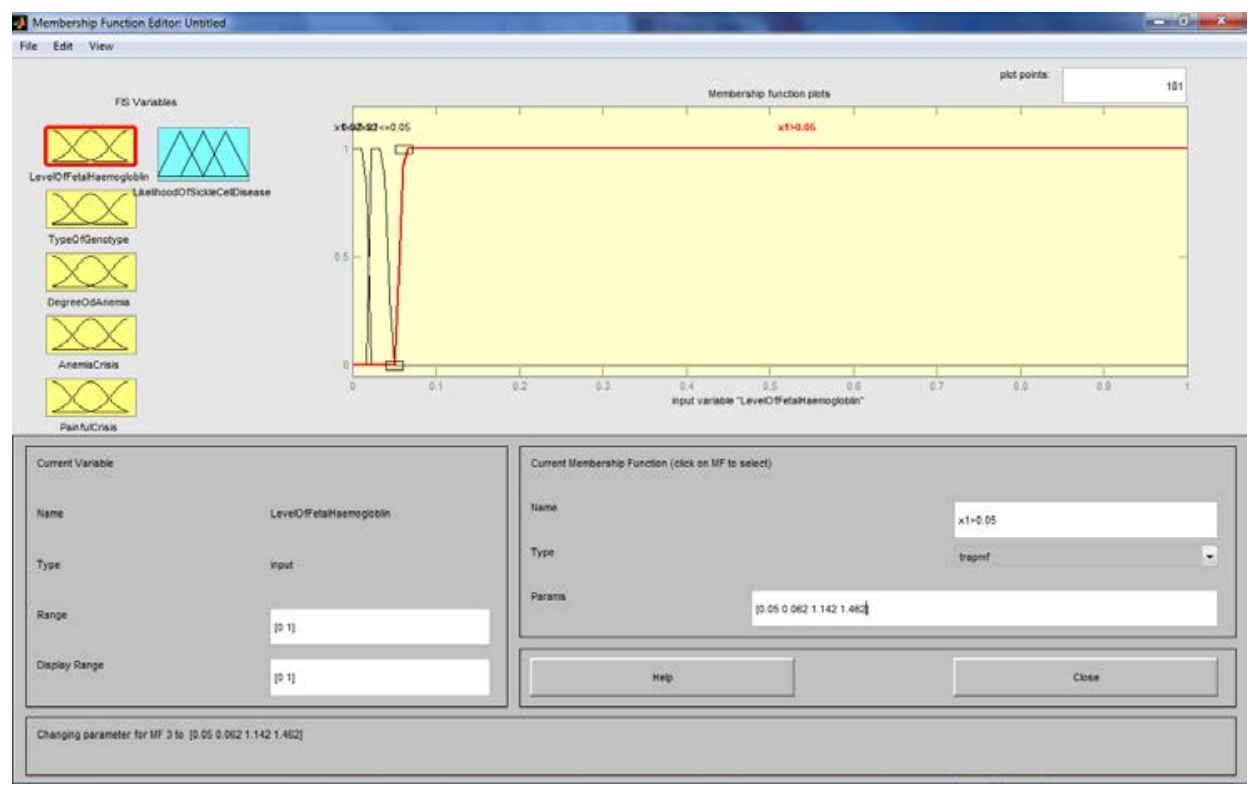

Figure 3: Membership function for the Level of Fetal Haemoglobin

b. Type of genotype, $\times 2$ (Figure 4)

- $\mathrm{SS} ; x_{2}=0$ $\operatorname{trimf}[x 2 ;-0.5,0,0.44]$ $\operatorname{trimf}[\mathrm{x} 2 ;-0.5,0,0.44]$

$$
=\left\{\begin{array}{cc}
0, & x 2 \leq-0.15 \\
\frac{x 2+0.5}{0.5}, & -0.15 \leq x 2 \leq 0 \\
\frac{0.44-x 2}{0.44}, & 0 \leq x 2 \leq 0.44 \\
0, & 0.44 \leq x 2
\end{array}\right\}
$$

- $\quad \mathrm{SE} ; x_{2}=1 \quad-\quad \operatorname{trimf}[\mathrm{x} 2 ; 0.5,1,1.44]$

trimf $[\mathrm{x} 2 ; 0.5,1,1.44]$

$$
=\left\{\begin{array}{cc}
0, & x 2 \leq-0.15 \\
\frac{x 2-0.5}{0.5}, & -0.15 \leq x 2 \leq 1 \\
\frac{1.44-x 2}{0.44}, & 1 \leq x 2 \leq 1.44 \\
0, & 1.44 \leq x 2
\end{array}\right\}
$$

$\quad \mathrm{S}^{*} ; x_{2}=2$

$\operatorname{trimf}[x 2 ; 1.5,2,2.44]$ 


$$
\operatorname{trimf}[\mathrm{x} 2 ; 1.5,2,2.44]=\left\{\begin{array}{cc}
0, & x 2 \leq 1.15 \\
\frac{x 2-1.5}{0.5}, & 1.15 \leq x 2 \leq 2 \\
\frac{2.44-x 2}{0.44}, & 2 \leq x 2 \leq 2.44 \\
0, & 2.44 \leq x 2
\end{array}\right\}
$$

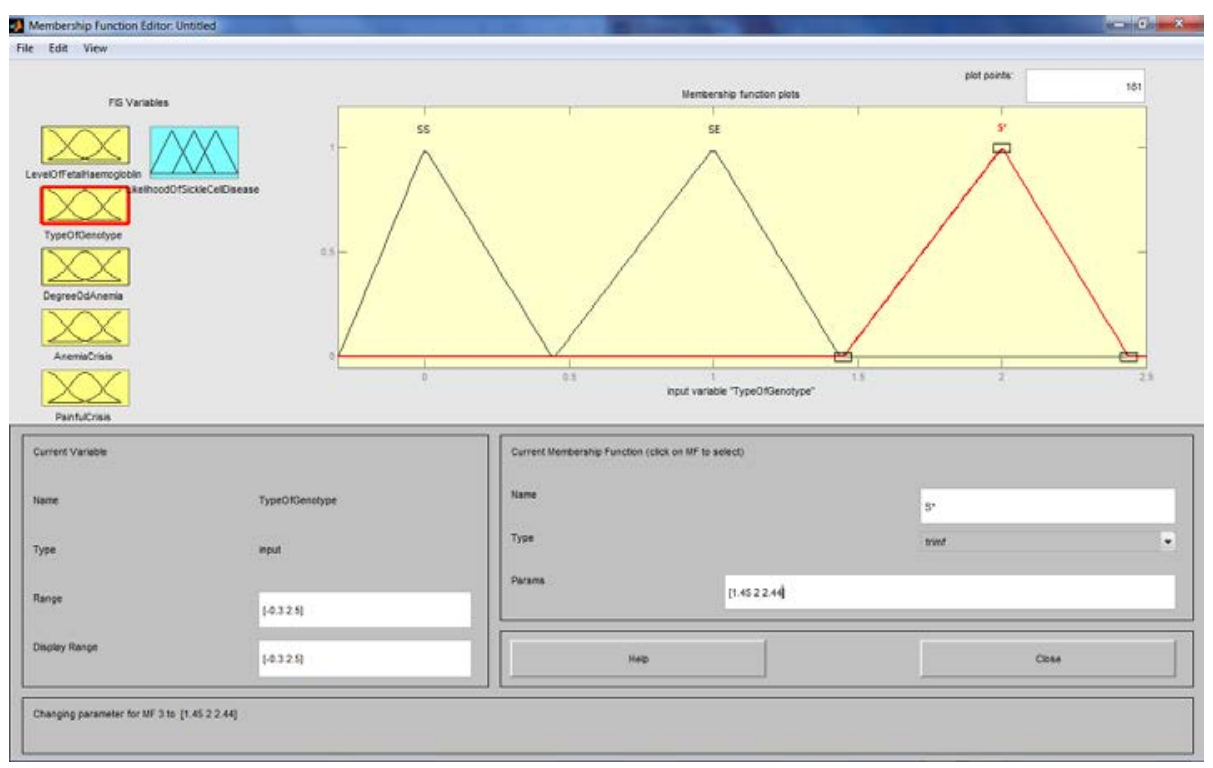

Figure 4: Membership function for the type of genotype

\section{c. Degree of anemia, x3 (Figure 5)}

- $x_{3}<0.15$

trapmf[x3; $[0,0.001,0.011,0.0144]$

trapmf $[\mathrm{x} 3 ;[0,0.001,0.011,0.0144]$

$$
=\left\{\begin{array}{cr}
0, & x 3 \leq 0 \\
\frac{x 3}{0.001}, & 0 \leq x 3 \leq 0.001 \\
1, & 0.001 \leq x 3 \leq 0.011 \\
0.011-x 3 & 0.011 \leq x 3 \leq 0.0144 \\
0.0034 & 0.0144 \leq x 3
\end{array}\right\}
$$

- $\quad x_{3} \geq 0.15 \quad-\quad \operatorname{trapmf}[\times 3 ; 0.015,0.02,0.99,1]$

trapmf $[\mathrm{x} 3 ; 0.015,0.02,0.99,1]$

$$
=\left\{\begin{array}{cc}
0, & x 3 \leq 0.015 \\
\frac{x 3-0.015}{0.005}, & 0.015 \leq x 3 \leq 0.02 \\
1, & 0.02 \leq x 3 \leq 0.99 \\
\frac{0.99-x 3}{0.01}, & 0.99 \leq x 3 \leq 1 \\
0, & 1 \leq x 3
\end{array}\right\}
$$




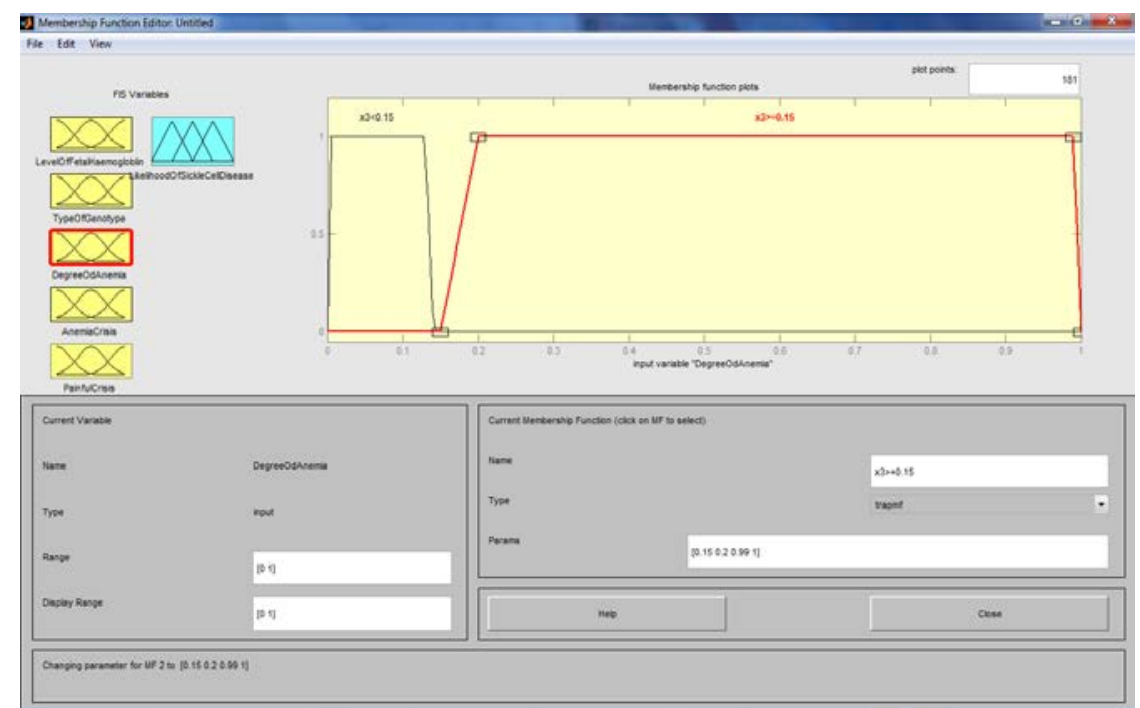

Figure 5: Membership function for the degree of Anemia

\section{d. Likelihood of Sickle-cell disease, y (Figure 6)}

- No; $y=0$

$$
\operatorname{trimf}[y ;-0.5,0,0.44]=\left\{\begin{array}{c}
0, \\
\frac{y+0.5}{0.5} \\
\frac{0.44-y}{0.44} \\
0,
\end{array}\right.
$$

trimf $[y ;-0.5,0,0.44]$

$$
\left.\begin{array}{c}
y \leq-0.5 \\
-0.5 \leq y \leq 0 \\
0 \leq y \leq 0.44 \\
0.44 \leq y
\end{array}\right\}
$$

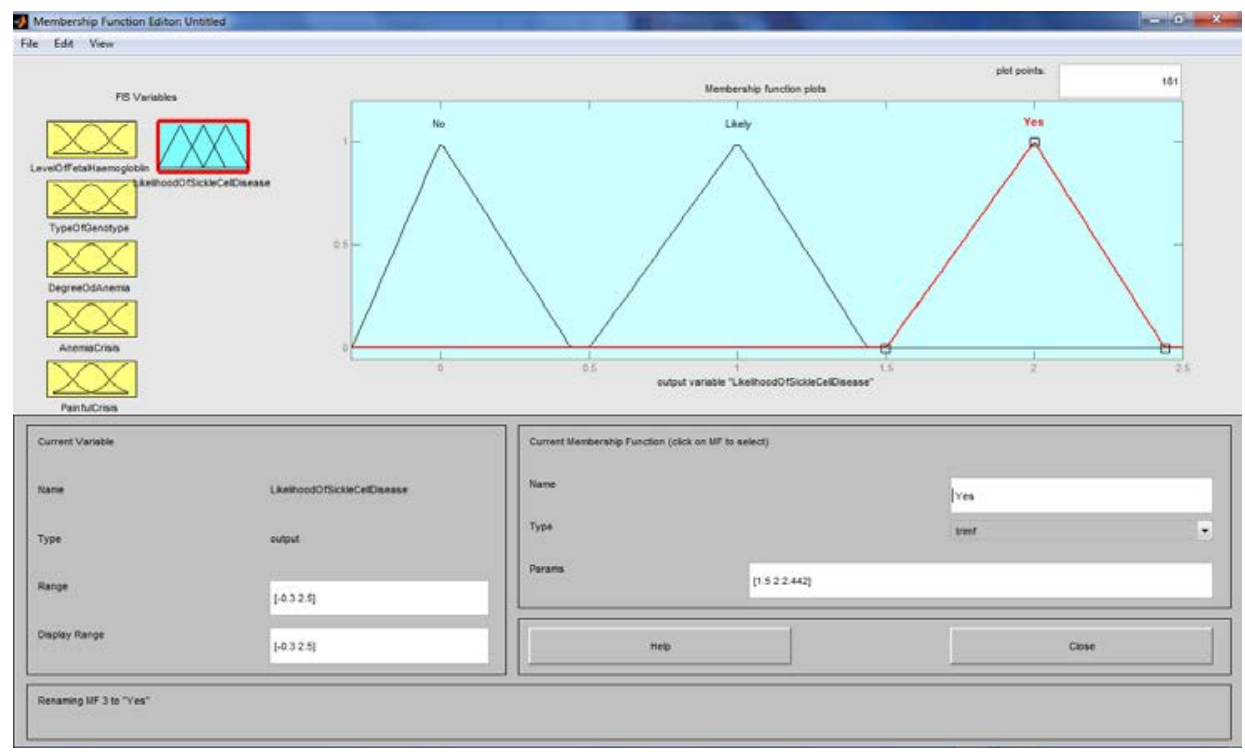

Figure 6: Membership function for the degree of Anemia 
Kehinde Oladipo Williams, Theophilus Adesola Aladekomo and Adebayo Peter Idowu; Prediction Model for Likelihood of Survival of Sickle-Cell Anaemia (SCA) among Peadiatric Patients using Fuzzy Logic, Transactions on Networks and Communications, Volume 3 No 1, Feb (2015); pp: 31-44

\subsection{Inference engine development, aggregation and defuzzification}

After developing the membership function, the process of developing the fuzzy inference engine which makes use of the 18 different rules shown in Table 2 below is necessary. It is with the information about the membership functions i.e. the labels that have been used to map each interval of membership functions e.g. Genotype had labels: SS, SE and $\mathrm{S}^{*}$ that the rules were been formed.

Hence, each rules that was provided is a result of a case-based reasoning approach which involves the experience that the expert had had in the years have shown such pattern except otherwise cases where there were misdiagnosis (false positives) or undiagnosis (cases not yet understood).

For the purpose of this study and the variables that are considered - the And Method used in evaluating each degree of membership is Minimum (it selects the smallest value of many), the Or Method used is the Maximum (it selects the largest value out of many); which although is not used in this study and the Implication Method used is the Minimum. These fuzzy operators were used to calculate the output for each rules which now require aggregation to be applied in order to get a single output.

The Aggregation method used in determining the optimum output membership function for the output is chosen to be Maximum (it selects the largest value for every region of the output variable's membership function). This method was chosen since it is the most commonly used method of aggregating linear-wise membership functions like trapezoidal and triangular membership functions.

Table 2: Fuzzy rules developed for the inference system

\begin{tabular}{|c|c|c|c|c|}
\hline № & $\begin{array}{c}\text { Hemoglobin } \\
\text { level }\end{array}$ & Genotype & $\begin{array}{c}\text { Degree of } \\
\text { Anemia }\end{array}$ & $\begin{array}{c}\text { Sickle Cell } \\
\text { Survival } \\
\text { (Yes/No) }\end{array}$ \\
\hline 1 & $<=2 \%$ & SS & $<15 \%$ & No \\
\hline 2 & $<=2 \%$ & SS & $>=15 \%$ & No \\
\hline 3 & $<=2 \%$ & SE & $<15 \%$ & No \\
\hline 4 & $<=2 \%$ & SE & $>=15 \%$ & Yes \\
\hline 5 & $<=2 \%$ & $\mathrm{~S}^{*}$ & $<15 \%$ & No \\
\hline 6 & $<=2 \%$ & $\mathrm{~S}^{*}$ & $>=15 \%$ & Yes \\
\hline 7 & $2 \%<$ level<=5\% & SS & $<15 \%$ & No \\
\hline 8 & $2 \%<$ level<=5\% & SS & $>=15 \%$ & Yes \\
\hline 9 & $2 \%<$ level<=5\% & SE & $<15 \%$ & Yes \\
\hline 10 & $2 \%<$ level< $<=5 \%$ & SE & $>=15 \%$ & Yes \\
\hline 11 & $2 \%<$ level<=5\% & $\mathrm{S}^{*}$ & $<15 \%$ & Yes \\
\hline 12 & $2 \%<$ level<=5\% & $\mathrm{S}^{*}$ & $>=15 \%$ & Yes \\
\hline 13 & $>5 \%$ & SS & $<15 \%$ & No \\
\hline 14 & $>5 \%$ & SS & $>=15 \%$ & Yes \\
\hline 15 & $>5 \%$ & SE & $<15 \%$ & Yes \\
\hline 16 & $>5 \%$ & SE & $>=15 \%$ & Yes \\
\hline 17 & $>5 \%$ & $\mathrm{~S}^{*}$ & $<15 \%$ & Yes \\
\hline 18 & $>5 \%$ & S* & $>=15 \%$ & Yes \\
\hline
\end{tabular}


The defuzzification of the output membership function resulting from the process of aggregation shows the crisp result that gives the likelihood of sickle cell disease as a real number value (a value within the range of the output variable's membership functions). In the case of this study the values 0 (or between 0 and 0.44 ) and 1 (or between 0.5 and 1.44) were used to identify No and Yes respectively. The method of defuzzification chosen for this study is the centroid method - it simply calculates the centre-of-gravity of the final polygon that results from the process of aggregation. It is also chosen for its compatibility with linear-wise membership functions.

Figure 7 shows the diagram of the simulated fuzzy logic system for the prediction of the likelihood of Sickle-cell disease in an individual given the values for three (3) input variables, namely: level of fetal haemoglobin, type of genotype and degree of anemia. This is the view of the fuzzy inference system using the fuzzy logic toolbox available in the MATLAB R2012a software used as the simulation environment.

The simulated fuzzy logic system is of the Mamdani type and consists of 3 and 1 fuzzified inputs and output variables and an inference engine which contains 18 IF-THEN rules describing expert knowledge - gathered via knowledge elicitation from expert.

This fuzzy logic system can be used to determine what the likelihood of sickle-cell disease will be; given a known set of clinical data on individuals which contain the under-listed variables. This will be used as a means of evaluating the accuracy of the system by putting into consideration the true and false positive outcomes.

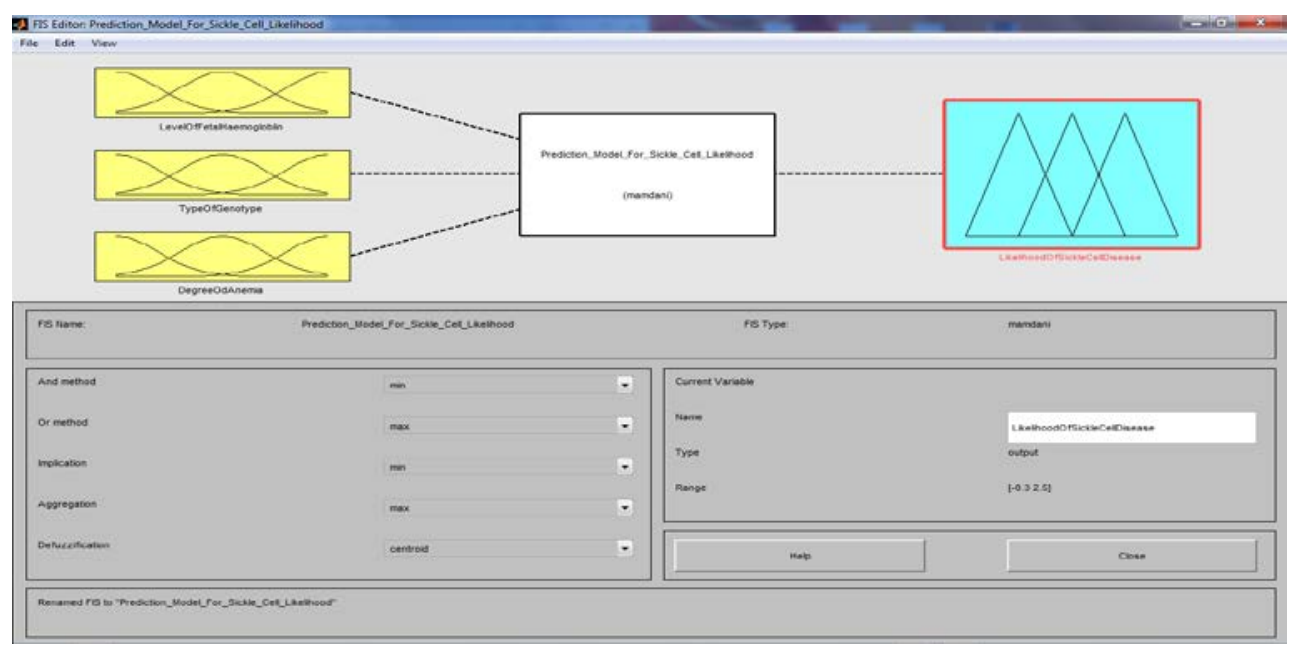

Figure 7: Proposed fuzzy inference system

\section{Results and Discussions}

After formulating the model necessary for simulating the fuzzy logic inference system - the model was implemented using the MATLAB Versions 7 software developed as Release 2012. The fuzzy logic toolbox which is among the many toolboxes available in the MATLAB software was used in simulating the predictive model using triangular and trapezoidal membership functions for the fuzzification of the input and output variables. The fuzzy logic system was used to perform a view of the surface diagram which shows the distribution of the many possible values and the relationship between any two variables.

Figure 8 gives a plot of the surface diagram showing the relationship between level of haemoglobin and the type of genotype; it can be observed that the diagram clearly shows that there is more likelihood of cases of people having haemoglobin levels above $2 \%$ to have SCA while cases having haemoglobin levels below $2 \%$ are more likely not to have SCD. The plot also shows that for all cases 
Kehinde Oladipo Williams, Theophilus Adesola Aladekomo and Adebayo Peter Idowu; Prediction Model for Likelihood of Survival of Sickle-Cell Anaemia (SCA) among Peadiatric Patients using Fuzzy Logic, Transactions on Networks and Communications, Volume 3 No 1, Feb (2015); pp: 31-44

of fetal haemoglobin levels with and SS genotype there is hardly any likelihood of the sickle-cell disease occurring but for cases where the genotype is either SE and $S^{*}$ the patients have a likelihood of SCD.

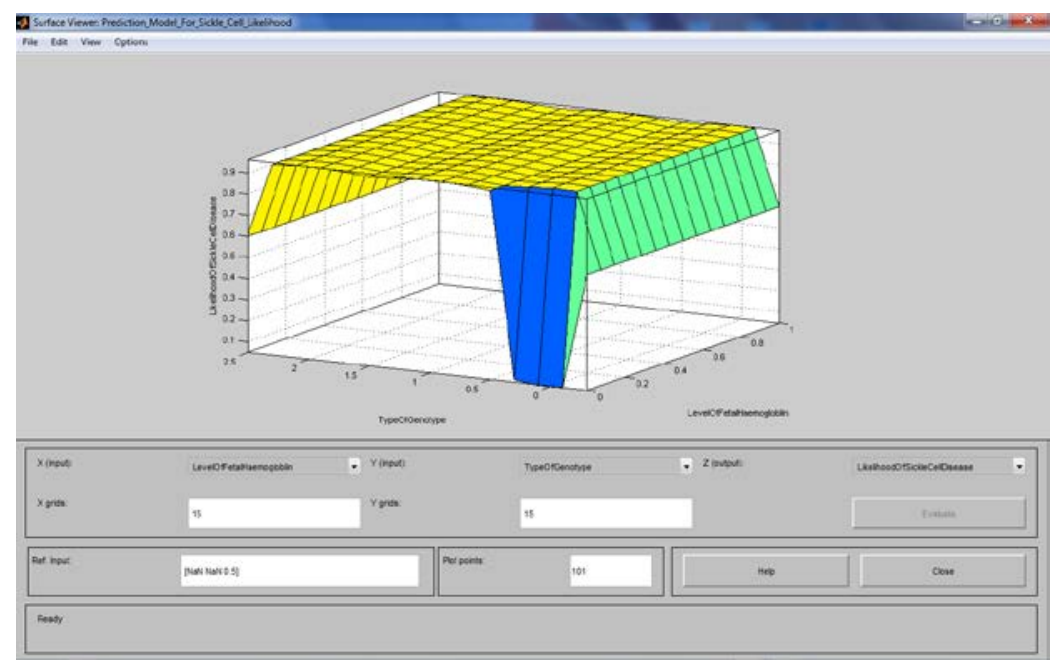

Figure 8: Surface diagram of fetal haemoglobin and genotype

Figure 9 shows the surface diagram having a plot of the relationship between the level of haemoglobin and the degree of anemia. It can be observed that for cases where the degree of anemia is less than $15 \%$ there is no likelihood of having SCD. And for cases where the level of fetal haemoglobin is less than or equal to $2 \%$ there is hardly the possibility of having SCA except where the genotype is SE or S*.

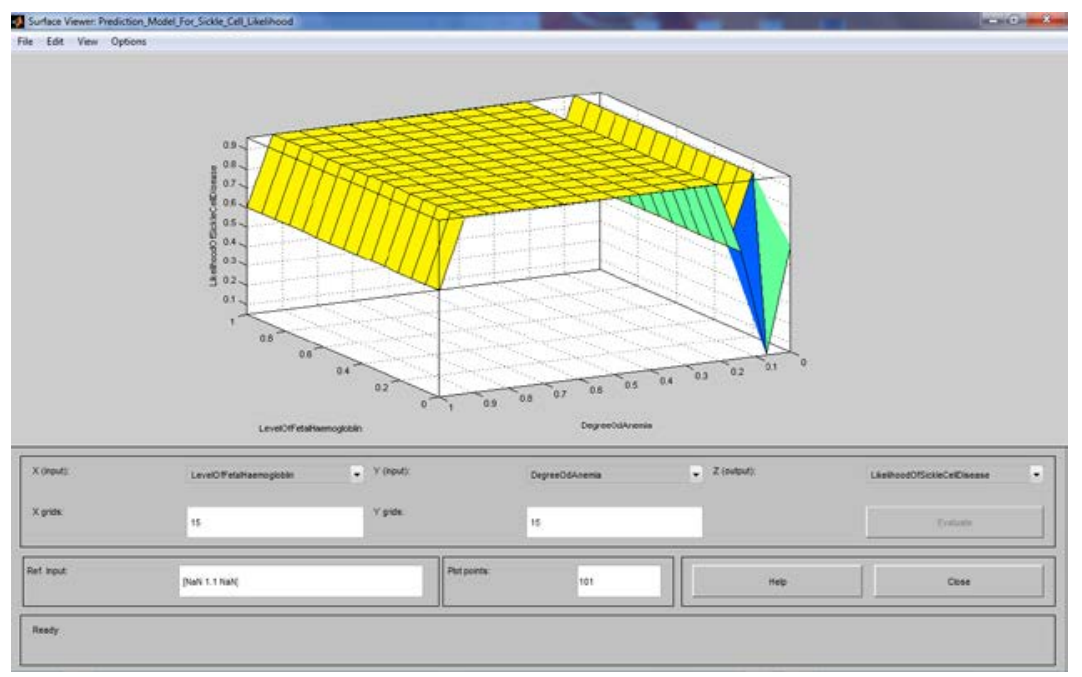

Figure 9: Surface diagram of the level of fetal haemoglobin and genotype

Figure 10 shows the surface diagram of the relationship that exists between the data values of the degree of anemia and the type of genotype of the patient. It was observed that whenever the genotype is SS there is no likelihood of SCA but when the level of fetal haemoglobin is less than or equal to $2 \%$ there is the likelihood of SCD. But for all cases where the degree of anemia is greater than or equal to $15 \%$ there is a likelihood of the existence of the SCD. 


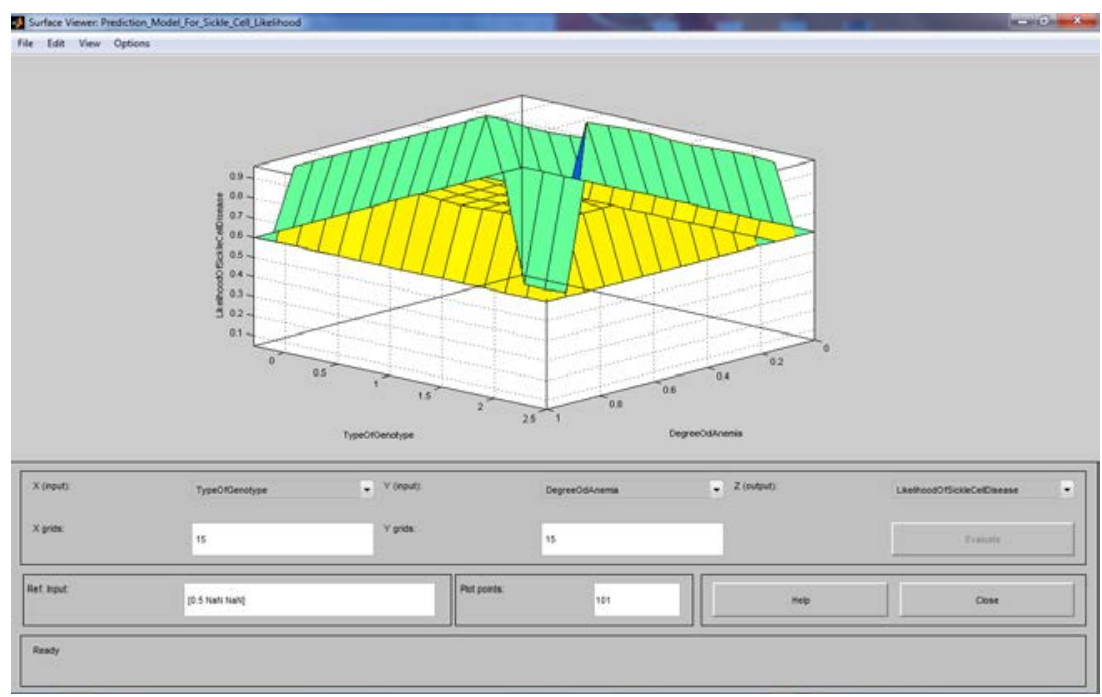

Figure 10: Surface diagram degree of anemia and genotype

\section{Conclusion}

The proposed model for the prediction of the likelihood of SCA was presented using 3 input variables namely: the level of fetal haemoglobin, degree of anemia and the type of genotype of the patient. The variables were identified and knowledge defining the relationship between variables was used in developing the inference system of the fuzzy inference system. The variables were all fuzzified and the fuzzified input variables were fed to the inference engine. The 18 output that were produced after the inference engine are aggregated to a single output which was defuzzified to get the crisp output i.e. No or Yes.

The model was simulated using the fuzzy logic toolbox available in the MATLAB software and the results of the behavior of the proposed model presented via the surface diagram. It is believed that this model will help diagnose the likelihood of SCA in an individual having provided a record containing the inputs as a 3-tuple. This model should help reduce the number of untimely deaths which occur as a result of late detection.

\section{REFERENCES}

[1]. Malowany, J. I., Butany, J. (2012). Pathology of sickle cell disease. Seminars in Diagnostic Pathology, 29(1), pg. 49-55.

[2]. Mishra, N., Jha, P. (2014) Framing Fuzzy Rules using Mamadani Model for Effective Sickle Cell Diagnosis. International Journal of Engineering Sciences and Research Technology. 3(6), June 2014, pg. 389-396, ISSN: 2277-9655.

[3]. Obeagu, E. I., Ogbuabor, B. N., Ikechukwu, O. A., Chude, C. N. (2014) Haematological parameters among sickle cell anemia patients' state and haemoglobin genotype AA individuals at Michael Okpara University of Agriculture, Umudike, Abia State, Nigeria. International Journal of Current Microbiology and Applied Sciences; 3(3), pg. 1000 - 1005, ISSN: 2319-7706. 
Kehinde Oladipo Williams, Theophilus Adesola Aladekomo and Adebayo Peter Idowu; Prediction Model for Likelihood of Survival of Sickle-Cell Anaemia (SCA) among Peadiatric Patients using Fuzzy Logic, Transactions on Networks and Communications, Volume 3 No 1, Feb (2015); pp: 31-44

[4]. Omoti, C. E.2005. Haematological Values in Sickle Cell Anaemia in Steady State and During Vaso-occlusive Crisis in Benin City, Nigeria Annals of African Medicine, 42, pg.62-67.

[5]. Pauling, L., Itano, H.A., Singer, S. J., Wells, I. C. (1949). Sickle Cell Anaemia: a Molecular Disease. Journal of Science 110, pg. 543-548.

[6]. Ukpong, E. (1992) Current Concepts in the Management of Sickle Cell Disorders. Kraft Books, Ibadan.

[7]. Wellems, T. E., Hayton, K., Fairhurst, R. M. (2009). The impact of malaria parasitism: from corpuscles to communities. Journal of Clinical Investment; 119 (9), pg. 496-505.

[8]. Aramideh, J., Jelodar, H. (2014) Application of Fuzzy logic for presentation of an expert system to diagnose anemia. Indian Journal of Science and Technology, 7(7), pg. 933-938, July 2014. ISSN: 0974-6846.

[9]. Sayyahi, H. (2008). An application of fuzzy case based reasoning for poison classification. Unpublished Masters in Information Technology Thesis. University of Malaysia.

[10]. Goyal, D. (2006) Disease Diagnostic System using LabVIEW. Unpublished Masters of Engineering in Electronics Instrumentation and Control Engineering Thesis. Thapar Institute of Engineering and Technology, Deemed University, Punjab. 